Editors' Note: In reference to "Pearls \& Oy-sters: Ocular ischemic syndrome," Dr. Venketasubramanian questions the use of the Valsalva maneuver over breath-holding to assess cerebrovascular reserve and points out a possible error in the text of the article. The authors explain their methodology and agree with his correction. Dr. Sethi and author Tenney discuss Rasmussen encephalitis as another differential diagnosis in the case of a 21-month old boy with hemiconvulsion-hemiplegia-epilepsy.

Megan Alcauskas, MD, and Robert C. Griggs, MD

\section{PEARLS \& OY-STERS: OCULAR ISCHEMIC SYNDROME}

Narayanaswamy Venketasubramanian, Yohanna

Kusuma, Singapore: I read with great interest the case report by Fernandez-Torron et al. ${ }^{1}$ The authors state: "Right middle cerebral artery flow did not change with Valsalva maneuver." Could the authors clarify why a Valsalva maneuver was performed? If the aim was to assess cerebrovascular reserve, perhaps breath-holding would have been more appropriate to assess capacity/ reserve to vasodilate further?

There may also be an error in the text. While the text reported common carotid artery (CCA) occlusion by ultrasound, the angiogram showed (rightly) internal carotid artery (ICA) occlusion, I believe it is ICA occlusion. From the text: "Duplex carotid ultrasonography revealed occlusion of the initial portion of the right common carotid artery. Figure 2 Selective carotid arteriography (A) Arterial angiography (sagittal view) reveals a complete occlusion of the right internal carotid artery origin."

Author Response: Jose-Alberto Palma, Roberto Fernandez-Torron, Inmaculada Pagola, Pamplona, Spain: We thank Dr. Venketasubramanian for his comments and it would be useful to clarify some issues.

As Dr. Venketasubramanian points outs, breath holding is more appropriate to assess cerebrovascular reserve than the Valsalva maneuver. Our protocol comprises first a breath-holding maneuver after a normal inspiratory breath for a first estimation of cerebral vasomotor reactivity. We then ask our patients to perform a breath-holding maneuver after maximal inspiration (i.e., Valsalva maneuver) which can be also used for cerebrovascular reserve-although less appropriately than breath-holding. At the same time, it is used to screen for right-to-left shunts.

Dr. Venketasubramanian is also correct regarding the second point: the Duplex carotid ultrasound revealed an occlusion in the initial portion of the right internal carotid artery (as shown in figure 2) and not in the right common carotid artery as incorrectly mentioned in the text. ${ }^{1}$

Editors' Note: A correction regarding the occlusion appears on page 2368 .

(C) 2012 American Academy of Neurology

1. Fernandez-Torron R, Palma J-A, Pagola I. Pearls \& Oy-sters: ocular ischemic syndrome. Neurology 2012;79:e92.

\section{CHILD NEUROLOGY: HEMICONVULSION-} HEMIPLEGIA-EPILEPSY SYNDROME

Nitin K. Sethi, New York: I read with interest the clinical case of a 21-month-old boy with hemiconvulsion-hemiplegia-epilepsy (HHE) syndrome reported by Drs. Tenney and Schapiro. ${ }^{1}$ The authors do not mention Rasmussen encephalitis (RE) - also known as chronic focal encephalitis. In the acute stage, $\mathrm{RE}$ may have a presentation identical to the authors' case with frequent and often intractable seizures, regression of motor skills and speech, hemiparesis, and cognitive decline. The disorder is classically characterized by inflammation of one hemisphere and in the acute phase patients may present with focal onset seizures and almost no hemiparesis. Progression of the disease course is accompanied by increased frequency of focal motor seizures and development of hemiparesis and cerebral hemiatrophy. Steroids and IV immunoglobulin are beneficial both in the acute stage as shortterm high dose therapies as well as in lower doses for long-term treatment. Seizures are generally refractory to standard anti-epileptic drugs and hemispherectomy may be palliative.

Author Response: Jeffrey R. Tenney, Cincinnati: I thank Dr. Sethi for his interest in our article and the insightful comments. Rasmussen encephalitis (RE) could have an acute clinical presentation similar to that seen in the patient we described. It has been reported that $20 \%$ of patients with RE can have status epilepticus as the initial manifestation and, as mentioned, these patients often have loss of motor/language skills as well as the development of hemiparesis and 
cerebral hemiatrophy. ${ }^{2}$ I believe that a factor distinguishing RE from hemconvulsion-hemiplegia-epilepsy (HHE) syndrome in our case was the timing of symptoms/imaging findings and the clinical course of our patient since that time. The progression of RE has been classically divided into 3 stages, with stage 1 (from onset of seizures and before development of hemiparesis) reported to have a mean duration of 2.8 years (range 3 months to 10 years). ${ }^{2}$ This is in contrast to our patient, who had onset of seizures and development of hemiparesis within 5 days or less. In addition, most patients with RE will have recurrent, medically refractory seizures while those with HHE syndrome will usually have a seizure free period (months to years) after the initial presentation before they might develop refractory seizures.

(C) 2012 American Academy of Neurology

1. Tenney JR, Schapiro MB. Child neurology: hemiconvulsion-hemiplegia-epilepsy syndrome. Neurology 2012;79: e1-e4.

2. Oguni H, Andermann F, Rasmussen T. The natural history of the syndrome of chronic encephalitis and epilepsy: a study of the MNHI series of forty-eight cases. In Anderman F, editor. Encephalitis and Epilepsy: Rasmussen's Syndrome. London: Butterworth-Heinemann; 1991: $7-35$.

\section{CORRECTION}

\section{Pearls \& Oy-sters: Ocular ischemic syndrome}

In the Resident \& Fellow article "Pearls \& Oy-sters: Ocular ischemic syndrome" by R. Fernandez-Torron et al. (Neurology ${ }^{\circledR}$ 2012;79:e92-e94), there is an error in the text. Duplex carotid ultrasonography revealed occlusion of the initial portion of the right internal carotid artery (as shown in figure 2), not the right common carotid artery. The authors regret the error. 


\title{
Neurology
}

\author{
Child Neurology: Hemiconvulsion-hemiplegia-epilepsy syndrome \\ Nitin K. Sethi and Jeffrey R. Tenney \\ Neurology 2012;79;2367-2368 \\ DOI 10.1212/01.wnl.0000424157.07211.bf
}

This information is current as of December 10, 2012

\section{Updated Information \&} Services

References

Permissions \& Licensing

Reprints including high resolution figures, can be found at: http://n.neurology.org/content/79/24/2367.2.full

This article cites 1 articles, 1 of which you can access for free at: http://n.neurology.org/content/79/24/2367.2.full\#ref-list-1

Information about reproducing this article in parts (figures,tables) or in its entirety can be found online at:

http://www.neurology.org/about/about_the_journal\#permissions

Information about ordering reprints can be found online:

http://n.neurology.org/subscribers/advertise

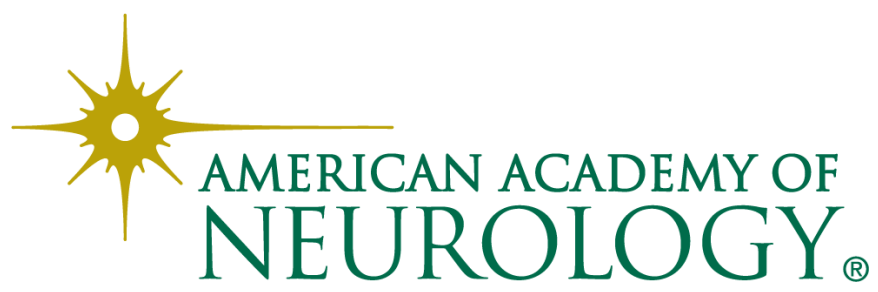

